\title{
Autoimmune hepatitis
}

INSERM

\section{Source}

INSERM. (1999). Orphanet: an online rare disease and orphan drug data base.

Autoimmune hepatitis. ORPHA:2137

Chronic autoimmune hepatitis $(\mathrm{AIH})$ is a rare progressive inflammatory disorder of unknown cause primarily affecting women and associated with circulating autoantibodies, elevated transaminase levels, and increased levels of immunoglobulin. 